\title{
Human-Animal Relationship: A Comparative Study in Working and Breeding Horses
}

\author{
Silvana POPESCU ${ }^{1 *}$, Cristin BORDA ${ }^{1}$, Daniela OROS $^{1}$, Dana C SANDRU ${ }^{1}$, Marina SPINU ${ }^{1}$, Radu GIUPANA ${ }^{1}$, \\ Eva DIUGAN ${ }^{2}$
}

${ }^{1}$ Faculty of Veterinary Medicine, University of Agricultural Sciences and Veterinary Medicine, Manastur Street, no. 3-5, 400372, Cluj-Napoca, Romania

${ }^{2}$ Beclean Studfarm, The National Forest Administration Romsilva, Petricani Street, no. 9A, 023841,

Bucuresti, Romania

*corresponding author: silvana.popescu@usamvcluj.ro

Bulletin UASVM Veterinary Medicine 73(2) / 2016,

Print ISSN 1843-5270; Electronic ISSN 1843-5378

DOI:10.15835/buasvmcn-vm: 12172

\begin{abstract}
The importance of a good human-horse relationship in every equestrian discipline is recognized by the specialists all over the world. The aim of the study was to comparatively assess the behavioural response towards humans in different horse categories, in two seasons. The human-animal relationship was investigated during a year, in two different seasons in working horses (171 in the winter, 168 in the summer), stallions (62 in the winter, 66 in the summer) and broodmares and young horses (137 in the winter, 146 in the summer). Using specific methods, the general attitude of the horses was evaluated (apathetic or alert) and their reactions (aggressiveness, fear/avoidance, indifference, friendliness) to the: (1) assessors' approach (2) walking besides and (3) the attempt of touching the animal. The data were analyzed using the SPSS statistical software. The value of minimal significance was considered at $\mathrm{P}<0.05$. The proportion of the apathetic horses recorded in this study varied from $0 \%$ to $3.23 \%$ depending on the assessed category and season, without statistically significant differences $(P>0.05)$. For the behavioural responses (aggressiveness, fear, indifference or friendly response), statistically significant differences $(\mathrm{P}<0.05)$ were found among the assessed horse categories. The season had no significant influence on the variability of responses in the behavioural tests in none of the horse categories. The results indicate an inadequate human-animal relationship in all the studied horse categories, with negative implications on the welfare of the animals. This problem has low remedial possibilities, because it needs human mentality change of those working with horses.
\end{abstract}

Keywords: behavioural tests, breeding horses, human-horse relationship, working horses

\section{INTRODUCTION}

The importance of providing a good humanhorse relationship in all equestrian disciplines is recognized by the scientific literature nowadays, all over the world. Irrespective to the domain in which the horses are used, the positive interactions between them and the people working around have multiple beneficial effects, both for the welfare of the horses and for their performance and in the same time for the efficiency and safety of the human workers (Baraglia et al., 2011, Sankey et al., 2010).

Comparing with other farm animal species, in whose breeding and raising technology the human intervention is not that significant (for example in the beef producing cattle), when it comes about horses, the interactions with humans are indispensable, frequent and permanent, regardless of the use of these animals. It is considered that avoidance of mental stress is extremely important 
for the habituation and desensitization of the horses to their environment and for the reduction of their instinctual avoidance response (by running away) and fear (Murphy and Atkins, 2007).

Besides the environmental stimuli that can be perceived by the horse to be dangerous or frightening, triggering negative mental states (unusual sounds, new and especially moving objects, and so on) there are many events that can be perceived as being aversive. For example, part of the routine procedures, such as the veterinary actions (blood sampling, vaccinations, treating the sick horses, etc), hoof trimming, shoeing and even habituation with the harnesses and different works (cart pulling, riding) can receive negative mental connotations and can be associated with unpleasant states by the horse. In these situations, the behaviour of the person who restrains the horse can have a powerful impact on the later experiences of that type. Applying physical force, correcting the behaviour of the animal by hitting, using loud voice and scaring behaviours do not do any good but accentuate more the negative perception of the animal and link this type of contexts with something unpleasant. The more negative are the interactions between the horse and the person who restrains it, the more the horse will avoid these interactions and will display behavioural reactions of fear (Hausberger et al., 2008), especially when the situations are repeated. Besides the stressful and negative impact of these situations on the mental state of the horse, in fact these are the most dangerous scenarios for the people involved in these manoeuvres. A scared, disobedient animal, trying to avoid the procedures to which is subjected to, poses high risk of danger for the physical integrity of itself and of the people around.

This study aimed to enlist among recent researches regarding the assessment of the human-animal relationship in horses of different categories, a domain which is scarcely studied in Romania. The aim of the study was to comparatively assess the behavioural response towards humans in different horse categories, in two seasons.

\section{MATERIALS AND METHODS}

The study of the human-animal relationship was investigated on a sample formed by working horses (171 in the winter, 168 in the summer), breeding stallions (62 in the winter, 66 in the summer) and broodmares and young horses (137 in the winter, 146 in the summer). The breeding horses belonged to a national stud-farm and the working horses were owned by different private persons, in the same geographical area. The horses kept in the breeding farm were Furioso NorthStar, Lipizzaner and Romanian Draft horse breeds. The private working horses were of varying age categories and genders (Tab. 1).

The general attitude of the horses (apathetic or alert) was assessed and their reactions (aggressiveness, fear/avoidance, indifference, friendliness) to the: (1) assessors' approach (2) walking besides and (3) the attempt of touching the animal, by the methods described by Popescu and Diugan (2013). The approach was made at an angle of about $20 \%$ to the animals' body. Than the assessor stopped at about $30 \mathrm{~cm}$ from the head of the animal and recorded the horse's response. Then the assessor walked alongside the horse toward its rear and back again, maintaining a distance of approximately $30 \mathrm{~cm}$ from its body, recording any sign of the animal's attention. The physical contact was attempted by raising a cupped hand toward the horse's chin and touching it if the animal allowed the contact. All the horses were evaluated in two seasons, in the winter and in the summer, mainly the same animals. Each horse was assessed by two experimented assessors. The assessors were veterinarians; trained together in a preliminary study, until at least $80 \%$ intra- and

Tab. 1. The distribution of privately owned working horses depending on some descriptive parameters in the two assessment bouts

\begin{tabular}{ccc}
\hline Category & $\begin{array}{c}\text { Cold season } \\
(\mathrm{n}=171)\end{array}$ & $\begin{array}{c}\text { Warm season } \\
(\mathrm{n}=168)\end{array}$ \\
\hline Gender \\
\hline Mares & 110 & 108 \\
\hline Stallions & 22 & 22 \\
\hline Geldings & 39 & 38 \\
\hline 1 - 5 years & Age group & \\
\hline $5-15$ years & 107 & 41 \\
\hline Over 15 years & 23 & 104 \\
\hline & Phenotype \\
\hline Half heavy & 47 & 46 \\
\hline Medium & 89 & 87 \\
\hline Light & 35 & 35 \\
\hline
\end{tabular}


inter-assessor reliability was reached (Popescu and Diugan, 2013). The obtained data were analyzed using the SPSS statistical software. The data were compared using the Kruskal-Wallis test, because the Kolmogorov-Smirnov test showed abnormal distribution of the data. The effect of the season was investigated by the Wilcoxon test. The value of minimal significance was considered at $P$ $<0.05$

\section{RESULTS AND DISCUSSION}

Fig. 1 shows comparatively the percentage of the apathetic and alert horses within the assessed categories. Regarding the general attitude, there were no significant differences between the different horse categories. The fact that no apathetic animal was observed in the broodmares and young horses' categories is remarkable, probably because these animals had the benefit of free housing. The prevalence of apathetic horses was $2.34 \%$ in winter and $1.38 \%$ in summer in the working horses. In the breeding stallions' group $3.23 \%$ in winter and $3.03 \%$ in summer showed apathy. Within this study apathy was considered showing complete failure to respond to environmental stimuli (Popescu and Diugan, 2013). As long as the assessor was barely noticed by the animals being apathetic, the humananimal relationship in these cases was severely compromised.

In the few studies performed in Romania, the prevalence of the apathetic working horses does not exceed 10\%. Popescu and Diugan (2011) identify a percentage of $4.32 \%$ depressed horses within the 347 assessed animals, and $2.65 \%$ of the 715 studied horses, respectively (Popescu and Diugan, 2013). The highest percentage of apathetic horses recorded in a study performed in Romania is $7.72 \%$ of the 697 studied animals (Popescu et al., 2014). In much extended studies Pritchard et al. (2005) reports 8.1\% apathetic horses within 2071 working equines observed and Burn et al. (2010b) shows the same attitude in $13.7 \%$ of the 4504 assessed animals. In the case of the breeding horses the results are in agreement with those obtained by Sanmartín et al. (2015) showing that only the stallions displayed behavioural abnormalities.

The apathetic attitude, lack of response to the environmental stimuli, described in the working equines (Swann, 2006), is a chronic process that involves, besides accumulated tiredness, supplemented each day by the workload, other factors also, such as starvation and thirstiness, brutal manipulation by humans, pain (by lesions and diseases of the legs in the first place) and the lack of fulfilling of the basic behavioural needs of the animal. Loosing the interest for socializing with the conspecifics, even in the conditions in which this behaviour would be possible (after the end of the working day), is a visible manifestation of this process (Swann, 2006). Hall et al. (2008) states that when the training and management procedures are repeatedly unpleasant for the horse

\section{$\square$ Apathetic $\square$ Alert}

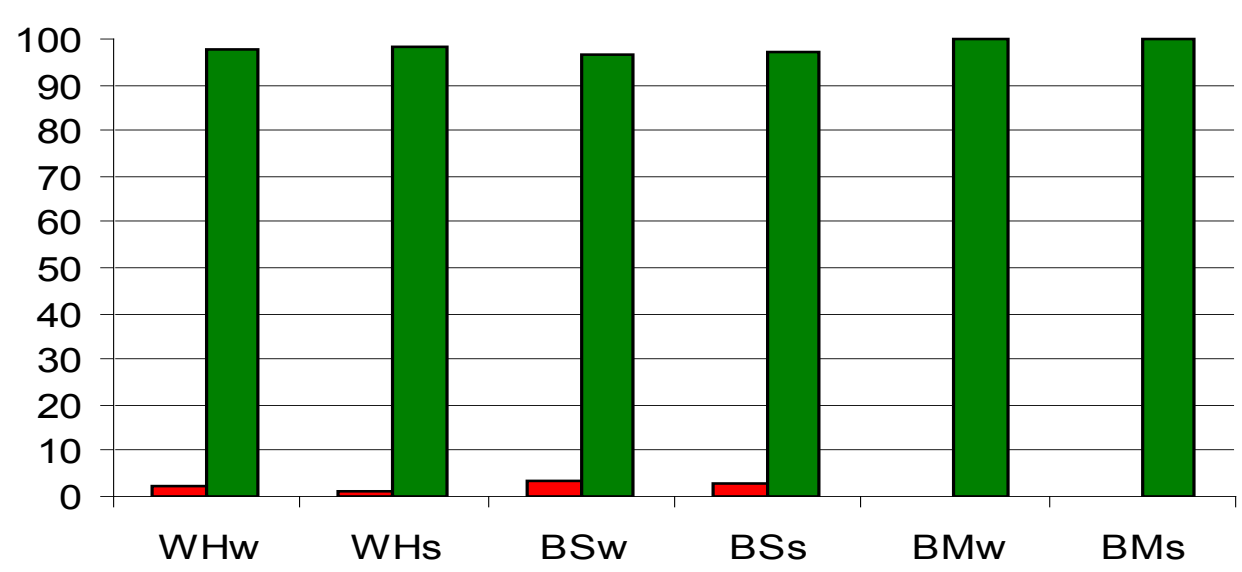

Note: $\mathrm{WHw}=$ working horses, in winter. WHs = working horses, in summer. BSw = breeding stallions, in winter. BSw = breeding stallions, in summer. BMw = broodmares and young horses, in winter. BMs = broodmares and young horses, in summer.

Fig.1. The prevalence of apathetic and alert horses within the assessed categories 
and there is no clear association between the own behaviour and the result, an interference can occur with the future learning process and performance level, in addition to compromising their welfare. The general image of the animal in this state is passivity, lack of motivation and depression. It can be found in different categories of use, beginning with the riding school horses (Hall et al., 2008) until the working draft horses. The owner or user of the horse in most of the cases will be pleased by the behaviour of this animal, which do not have unexpected, surprising reactions, always obeys to the tasks subjected to, is not very mobile, do not try to ,escape', not even when apparently would have the possibility. Sometimes the symptoms of this tiredness, burnout are not recognized by the user of the animal. In other cases this behaviour of the horse does not present interest or reflection means for their users, as long as it is a ,safe' animal, fulfilling the aim for which it is kept for. Probably for a large category of horse owners and users would be very difficult to understand the preference for a reactive horse, with initiative, perceived mostly as ,disobedience', comparing with a static one, which lacks reactions, even if the performance level is reduced in the latter.
The fact that in the present study the highest percentage of the apathetic animals was identified during the winter, in the stallions' category, could be related with displaying of learned helplessness. These horses, housed tethered, without considerable access to free movement, could have learn that regardless of the behavioural choices made, they can not escape from this situation of restraint and immobility. The season probably did not have an influence per se on the attitude of the horses, but the environmental conditions differed in the study, the horses being confined more, for longer times in the winter, comparing with the summer.

The responses of the working and breeding horses on the three behavioural tests are shown in Tab.2.

The proportion of the horses showing aggressiveness and fear was not significantly ( $\mathrm{P}>$ 0.05 ) different in the assessed categories in none of the three behavioural tests. The fact that none of the breeding stallions showed aggressiveness in the performed tests is remarkable.

Regarding the indifference and friendliness showed by the horses towards the assessors, there

Tab. 2. Human-related responses expressed as proportion (\%) of the working and breeding horses in each behavioural test

\begin{tabular}{|c|c|c|c|c|c|c|}
\hline \multirow[b]{2}{*}{ Behavioural observation } & \multicolumn{6}{|c|}{$\%$ within each season and category } \\
\hline & WHw & WHs & BSw & BSs & BMw & BMs \\
\hline \multicolumn{7}{|c|}{ Response to the approach of the assessor } \\
\hline Aggressiveness & 1.74 & 2.38 & 0.00 & 0.00 & 5.11 & 4.11 \\
\hline Fear/avoidance & 22.23 & 20.84 & 22.58 & 25.76 & 22.62 & 25.34 \\
\hline Indifference & $52.63^{\mathrm{a}}$ & $52.98^{\mathrm{a}}$ & $37.10^{\mathrm{ab}}$ & $30.30^{\mathrm{b}}$ & $16.05^{b}$ & $16.44^{\mathrm{b}}$ \\
\hline Friendliness & $23.40^{\mathrm{a}}$ & $23.81^{\mathrm{a}}$ & $40.32^{\mathrm{ab}}$ & $43.94^{\mathrm{ab}}$ & $56.40^{\mathrm{b}}$ & $54.11^{\mathrm{b}}$ \\
\hline \multicolumn{7}{|c|}{ Response to the assessor walking besides } \\
\hline Aggressiveness & 4.68 & 5.37 & 0.00 & 0.00 & 5.84 & 6.16 \\
\hline Fear/avoidance & 45.03 & 38.69 & 30.65 & 31.81 & 35.77 & 38.36 \\
\hline Indifference & 24.56 & 32.14 & 19.35 & 16.67 & 13.14 & 13.01 \\
\hline Friendliness & $25.15^{\mathrm{a}}$ & $23.80^{\mathrm{a}}$ & $50.00^{\mathrm{b}}$ & $51.52^{\mathrm{b}}$ & $45.25^{b}$ & $42.47^{b}$ \\
\hline \multicolumn{7}{|c|}{ Response to the touch of the assessor } \\
\hline Aggressiveness & 5.26 & 8.34 & 0.00 & 0.00 & 8.76 & 8.22 \\
\hline Fear/avoidance & 51.46 & 51.78 & 38.71 & 43.94 & 55.47 & 54.8 \\
\hline Indifference & $18.13^{\mathrm{ab}}$ & $19.05^{\mathrm{a}}$ & $16.13^{\mathrm{ab}}$ & $10.61^{\mathrm{ab}}$ & $8.03^{\mathrm{ab}}$ & $6.16^{\mathrm{b}}$ \\
\hline Friendliness & $25.73^{\mathrm{ab}}$ & $20.84^{\mathrm{a}}$ & $45.16^{b}$ & $45.45^{b}$ & $27.74^{\mathrm{ab}}$ & $30.82^{\mathrm{ab}}$ \\
\hline
\end{tabular}


were significant differences between the different horse categories.

Analyzing the data in Tab. 2, it can be observed that for each behavioural response type (aggressiveness, fear, indifference or friendliness) in the performed tests, the season and repetition of the assessment in most of the cases on the same animals had no significant influence. A study performed by Lansade and Bouissou (2008) demonstrates, by measuring several behavioural variables, the possibility of a temperamental trait in the horses named by the researcher ,reactivity towards humans'. The results of the tests show that this trait exists, regardless if the person is passive or active, familiar or unfamiliar for the horse and it is stable in time (Lansade and Boissou, 2008).

The three behavioural tests performed in this study can be considered together, as representing a gradual way to expose the animal to a stimulus (human presence) of whose intensity increases gradually, by increasing the spatial proximity between the assessor and the animal. The low speed of increasing the stimulus' intensity (the approach of the assessor step by step) and the breaks of 30-60 seconds between two successive tests have the role to allow the correct observation of the animal and also reassure continuously the animal that it will not be subjected to unpleasant experiences. If the evolution of the frequency of the same behavioural reaction is studied within the same category of horses during the three tests, their tendency of increasing or decreasing can be observed (Tab. 2).

If all the horse categories are considered together in all the three behavioural tests, it can be noticed that the prevalence of indifference is higher and that of the friendly reactions is lower, respectively, in the working horses. Correlations were reported between the lack of response in the assessed horses toward humans and some health and management problems (Ali et al., 2016; Burn et al., 2010a; Popescu et al., 2014). Taking into account the general welfare considerations, the friendly reaction of the horse towards people is the one most desired. By the other hand, the relationship between the horse and a human can be one of the most important factors for the safe usage of the animal (Hausberger and Muller, 2002). Sankey et al. (2010) show that a direct correlation exists between repeated positive horse-human interactions and the positive reactions and attitudes of the horses towards humans. Moreover, the horses have the ability to generalize the positive experiences related with a person by developing some positive mental associations and extending these to display positive attitudes also towards unfamiliar persons, towards people generally, and even in different situations than those in which the associations were produced. These generalizations can occur even after a relatively long time period, the positive memories persisting for a long term (Sankey et al., 2010). Moreover, the horses are able to retention and recall of the negative experiences. The more the human-horse interactions have negative connotations for the animal (stressful, scaring, painful), the longer and the more intense the horse will avoid future interactions that are similar and will display more pronounced fear responses (Hausberger et al., 2008). The partial or total lack of experience related with interactions with humans can intensify the negative perception even of some manoeuvres that are relatively nonstressful. Taking into account of all these, it can be said that the behaviour of those working with horse can have a great impact upon the way these animals see the interspecific interaction and react consequently in all those situations being in human proximity.

\section{CONCLUSION}

The results indicate improper human-animal relationship in all the studied horse categories, with negative impact on the welfare of the animals. This problem has low remedial possibilities, because it needs human mentality change of those working with horses.

\section{REFERENCES}

1. Ali AB, El Sayed AM, Matoock MY, Fouad MA, Heleski CR (2016). A welfare assessment scoring system for working equids-A methodfor identifying at risk populations and for monitoring progress of welfare enhancement strategies (trialed in Egypt). Appl Anim Behav Sci 176:52-62

2. Baraglia P, Maritia C, Petria L, De Giorgiob F, Sighieri C (2011). Does attention make the difference? Horses response to human stimulus after 2 different training strategies. J Vet Behav 6:31-38.

3. Burn CC, Dennison TL, Whay HR (2010a). Environmental and demographic risk factors for poor welfare in working horses, donkeys and mules in developing countries. Vet J 186(3):385-392.

4. Burn CC, Dennison TL, Whay HR (2010b). Relationships between behaviour and health in working horses, 
donkeys, and mules in developing countries. Appl Anim Behav Sci 126(3-4):109-118.

5. Hall C, Goodwin D, Heleski C, Randle H, Waran N (2008) Is there evidence of learned helplessness in horses? J Appl Anim Welf Sci 11(3):249-266.

6. Hausberger M, Muller C (2002). A brief note on some possible factors involved in the reaction of horses to humans. Appl Anim Behav Sci 76:339-344.

7. Hausberger M, Roche H, Henry S, Visser KE (2008). A review of the human-horse relationship. Appl Anim Behav Sci 109:1-24.

8. Lansade L, Boissou MF (2008). Reactivity to humans: a temperament trait of horses which is stable across time and situations. Appl Anim Behav Sci 114(3-4):492-508.

9. Murphy J, Arkins S (2007). Equine learning behaviour. Behav Process 76:1-13.

10. Popescu S, Diugan EA (2011). Welfare assessment of working horses through the use of animal linked parameters. Proceedings of the SAADC strategies and challenges for sustainable animal agriculture-crop systems 3:635-639.

11. Popescu S, Diugan EA (2013). The relationship between behavioural and other welfare indicators of working horses. J Equine Vet Sci 33:1-12.
12. Popescu S, Diugan EA, Spinu M (2014). The interrelations of good welfare indicators assessed in working horses and their relationships with the type of work. Res Vet Sci 96:406-414.

13. Popescu S, Borda C, Diugan EA, El Mahdy C, Spinu M, Sandru CD (2014). Human Related Indifference as a Working Horse Welfare Indicator. Bulletin UASVM Veterinary Medicine 71 (1):174-181.

14. Pritchard JC, Lindberg AC, Main DCJ, Whay HR (2005). Assessment of the welfare of working horses, mules and donkeys, using health and behaviour parameters. Prev Vet Med 69: 265-283.

15. Sankey C, Richard-Yris MA, Leroy H, Henry S, Hausberger M (2010). Positive interactions lead to lasting positive memories in horses Equus caballus. Anim Behav 79(4):869-875.

16. Sanmartín Sánchez L, Perea J, Blanco-Penedo I, PérezRico A, Vega-Pla JL (2015). Animal welfare in breeding horses (Equus Caballus): a comparative assessment in southern Spain. Rev Cient-Fac Cien V XXV(6):471-480.

17. Swann JW (2006). Improving the welfare of working equine animals in developing countries. Appl Anim Behav Sci 100:148-151. 